\title{
Predicting Carbides in Alloy Steels by Computer
}

\author{
Mats HILLERT \\ Professor, Division of Physical Metallurgy, The Royal Institute of Technology, S-100 44, Stockholm, Sweden.
}

\begin{abstract}
Today there is an established technique to evaluate the thermodynamic properties of individual phases in an alloy system by assessing all the thermochemical information and the information on the phase diagram. This technique has been applied to a large number of binary and some ternary systems. From a practical point of view it would find its most important applications in higher order systems which are found in alloy steels. This lecture will report on an effort to build a thermodynamic database for iron-base alloys, suitable for predicting the formation of various alloyed carbides in steels.
\end{abstract}

KEY WORDS: phase diagram; computer calculation; consistent database; alloyed carbides; high speed steel; cemented carbides; stainless steel.

\section{Introduction}

Phase diagrams are of a considerable practical importance to metallurgists. They have been determined experimentally and can be used directly for making various kinds of predictions. In this respect a phase diagram may be regarded as a rationalization of experimental data which has proved itself very useful. However, the phase diagram is also a manifestation of the thermodynamic properties of the system, a fact which results in useful rules of construction to be applied when constructing a phase diagram from limited experimental information. On the other hand, there has been a relatively weak interest in the thermodynamic properties themselves, probably because the information obtained directly from the phase diagrams has been sufficient for most needs.

In the last decade there has been a growing interest in correlating the phase diagram with the thermodynamic properties. In many cases one has tried to derive the thermodynamic properties from the phase diagram and has been satisfied if it is possible to recalculate a phase diagram in reasonable agreement with the experimentally determined diagram. More ambitious evaluations also take thermochemical and thermophysical information into account and, in fact, the full name of the specialized journal for this field is "CALPHAD-computer coupling of phase diagrams and thermochemistry". Of course, CALPHAD is an abbreviation of CALculation of PHAse Diagrams.

\section{Advantages of the Calphad Technique}

For binary and ternary systems the advantage of the Calphad technique is primarily that it results in more reliable phase diagrams but it should be realized that it may also give thermodynamic properties which were not available before. They can also be of considerable practical importance. They can be used for extrapolating phase boundaries into metastable ranges but also for evaluating driving forces for various transformation or evaluating the heat of transformation, just to mention a few examples.

For higher order systems the Calphad technique is even more important. Here it is practically impossible to obtain more than a few scattered pieces of experimental information but by the Calphad technique one obtains the whole phase diagram and all the thermodynamic properties. However, there is a considerable uncertainty involved. In the first step, a quaternary system is obtained as a prediction by combining the thermodynamic descriptions of the four ternary side-systems. If there is some quaternary information available, it can be used to test the prediction and if a significant discrepancy is found, it may be eliminated by introducing and evaluating quaternary interactions.

After such a test and modification, the recalculated phase diagram will be more reliable but there may still be surprises if new information becomes available later on from regions not examined before. This is a very serious limitation if one wants to predict the properties of a ternary system from the three binary side-systems. It is really necessary to take into account ternary interactions and they cannot be evaluated without ternary information. It is a less severe limitation if one wants to predict a quaternary system from the four ternary side-systems because quaternary interactions, i.e., interactions between four atoms of different kinds, are not so strong. It is an even less severe limitation if one wants to predict the properties of a quinary system from the five quaternary sidesystems. On the other hand, it should be emphasized that the Calphad technique cannot predict the appearance of a new phase in a higher order system from the properties of the lower order systems.

There are many commercial steels where four or more elements play an important role and the only practical way to rationalize available information and to make predictions when no direct information is available, is to use the Calphad technique. The present lecture will describe an effort to build a database for alloyed steels made at the Bivion of Physical 
Metallurgy at the Royal Institute of Technology (KTH) in Stockholm.

\section{Difficulty of Consistency}

In some binary alloy systems there is direct experimental information on the properties of the liquid phase over the whole range of composition. Using a computer-operated optimization procedure one can then assess various types of information at the same time, e.g., from calorimetric, emf and effusion studies, and evaluate model parameters to the best fit of the data. In the solid state this is rarely the case. There the compositional range of stability of each phase is usually limited but the model description of each phase may extend over the complete range of composition. Fig. 1 gives a simple example from the $\mathrm{Fe}-$ Cr system, where the fcc phase only exists up to about $11 \% \mathrm{Cr}$ but the thermodynamic description goes all the way to pure $\mathrm{Cr}$. The assessment of the $\mathrm{Fe}-\mathrm{Cr}$ system will thus result in a description of the properties of pure $\mathrm{fcc} \mathrm{Cr}$ which cannot be studied directly. In the first instant, it does not matter if that description is realistic or not as long as the stable part of the diagram is well represented. However, one will meet the same situation in the $\mathrm{Ni}-\mathrm{Cr}$ system and the two descriptions cannot be combined to yield the ternary $\mathrm{Fe}-\mathrm{Cr}$ system unless the same descriptions of $\mathrm{fcc} \mathrm{Cr}$ is used in both. This is demonstrated in Fig. 2.

As one goes from ternary systems to a quaternary, one realizes that any particular binary system appears in two of the ternary side-systems and they cannot be combined unless they are based on exactly the same descriptions of the binary. As a consequence, in order to build a database for higher order systems it is necessary to make the descriptions of all the lower order systems consistent. First, it is necessary to decide on the properties for each pure element in all possible states, at least bcc, fcc, hcp and liquid. Those descriptions are often called "lattice stabilities " after a proposal by Kaufman ${ }^{11}$ and a recommended set of lattice stabilities has recently been compiled by Dinsdale. ${ }^{2)}$ It would be a great advantage if all assessments could be based upon that compilation. Second, it is necessary to decide on the properties for each binary system but there we encounter the difficulty that different researchers often use different thermodynamic models and their assessments can not be combined.

Collaboration on a wide scale is only possible if there can be a general agreement on models to be used and, furthermore, on the actual numbers for each binary system. A very close contact between the collaborators is thus required and it may seem impossible ever to establish such a collaboration. However, an effort is made in Europe where seven laboratories collaborate under the name of SGTE (Scientific Group Thermodata Europe). That collaboration has been reasonably successful and a compilation of 129 binary phase diagrams has recently been completed. ${ }^{3)}$ All assessments of higher order

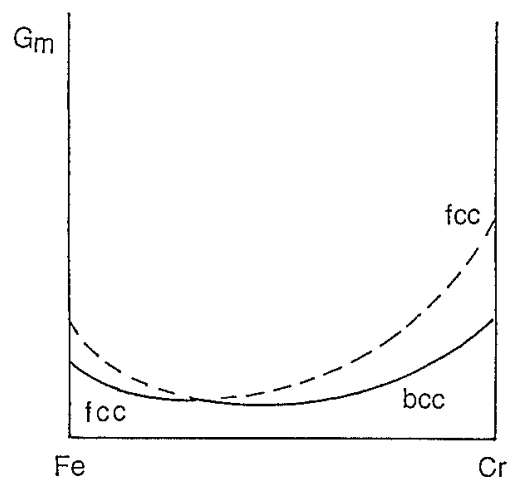

Fig. 1. Schematic molar Gibbs energy diagram for the $\mathrm{Fe}-$ Cr system at $1100^{\circ} \mathrm{G}$.

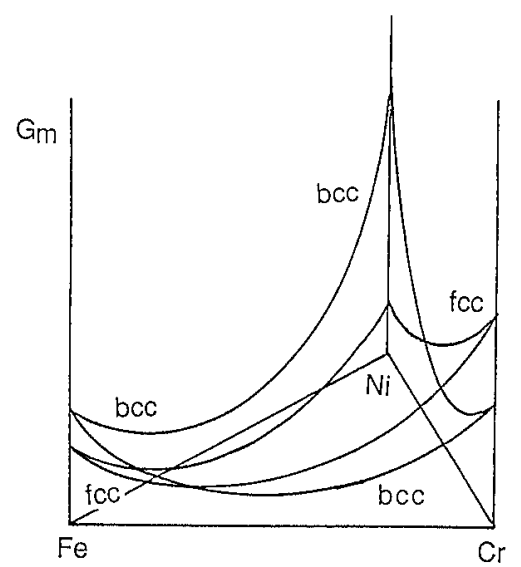

Fig. 2. Schematic molar Gibbs encrgy diagram for the $\mathbf{F e}-$ $\mathrm{Cr}-\mathrm{Ni}$ system at $1100^{\circ} \mathrm{C}$.

systems within SGTE should be based upon them and anybody who likes to contribute to a consistent database for higher order systems should base his or her work on these two compilations. In the future we can hope to see similar compilations of ternary systems.

\section{Study of Ternaries at KTH}

The study of ternary $\mathrm{Fe}-\mathrm{G}-X$ systems at $\mathrm{KTH}$ started more than 25 years ago when first Drs. Tsuguyasu Wada and Harue Wada' ${ }^{4}$ spent a year in Stockholm and then Dr. Taiji Nishizawa ${ }^{5,6)}$ spent two years. They were followed by a number of graduate students. Over the years the group has produced some experimental information on ternary systems but it may be more important that it has developed thermodynamic models and also computer programs for any type of equilibrium calculation, $\mathrm{POLY} \mathrm{Y}^{7}$, and for optimizing the values of model parameters to the best fit of experimental information, PARROT ${ }^{8)}$. These programs are now parts of a databank, THERMOCALC9). So far, ternaries of the type $\mathrm{Fe}-\mathrm{C}-X$ with $X$ being $\mathrm{Si}, \mathrm{Ti}, \mathrm{V}, \mathrm{Gr}, \mathrm{Mn}, \mathrm{Co}, \mathrm{Ni}, \mathrm{Nb}, \mathrm{Mo}$ and $\mathrm{W}$ have been completed. However, in order to combine them into higher order systems it is necessary to have descriptions of many other ternaries, without $\mathrm{Fe}$ or $\mathrm{G}$. There is still a long way to go until we have a complete description of the $1-\mathrm{Si}-\mathrm{Ti}-\mathrm{V}-\mathrm{Cr}-\mathrm{Mn}-\mathrm{Fe}-$ 
$\mathrm{Co}-\mathrm{Ni}-\mathrm{Nb}-\mathrm{Mo}-\mathrm{W}$ system. In fact, that goal is still out of sight and cannot be reached without the collaboration of many other groups. On the other hand, a reasonable description of the $\mathrm{Fe}$ rich part of that multicomponent system may soon be obtained. In order to give an impression of this work, some higher order systems will now be discussed.

\section{1. $\mathrm{Fe}-\mathrm{Cr}-\mathrm{Mo}-\mathrm{C}$}

The $\mathrm{Fe}-\mathrm{Cr}-\mathrm{Mo}-\mathrm{C}$ system contains two strong carbide formers, Gr and Mo, and, naturally, it was essential to assess the $\mathrm{Gr}-\mathrm{C}$ and $\mathrm{Mo}-\mathrm{C}$ binaries but also $\mathrm{Fe}-\mathrm{Cr}, \mathrm{Fe}-\mathrm{Mo}$ and Mo-Cr. It then became evident that the accepted lattice stabilities for $\mathrm{Gr}$ and Mo should be modified ${ }^{10}$ and the completed work thus comprised a complete reassessment of all the lower order systems except for $\mathrm{Fe}, \mathrm{C}$ and $\mathrm{Fe}-\mathrm{C}$. As an example, Fig. 3 gives the Mo-C system ${ }^{11}$ with a comparison of experimental phase diagram data.

The $\mathrm{Fe}-\mathrm{Cr}-\mathrm{C}$ system has been assessed several times but it was now necessary to evaluate it with the new lattice stabilities. From the assessment it was then possible to calculate various sections, ${ }^{12)}$ e.g., the vertical section at $13 \mathrm{wt} \% \mathrm{Cr}$ given in Fig. 4.

Among the ternaries we also find the $\mathrm{Fe}-\mathrm{Gr}-\mathrm{Mo}$ system which contains several intermetallic phases. Here it was necessary to make many experimental measurements. ${ }^{13)}$ The final result for $1373 \mathrm{~K}$ is shown in Fig. 5. It contains four intermetallic phases, $\sigma, \chi, \mathrm{R}$ and $\mu$. A comparison with some data from the same temperature is given in Fig. 6 but it should be realized that the result presented in Fig. 5 is the result of data from other temperatures, as well.

When all four ternaries had been assessed and were combined into the quaternary system, it became evident that one needs new information in order to describe the alloyed carbides. ${ }^{14)}$ As an example, quaternary information shows that $\mathrm{Cr}$ dissolves in the ksi carbide which is present in the Fe-Mo-C system. In principle, that effect can be represented by choosing a value for the Gibbs energy of the ksi carbide in the

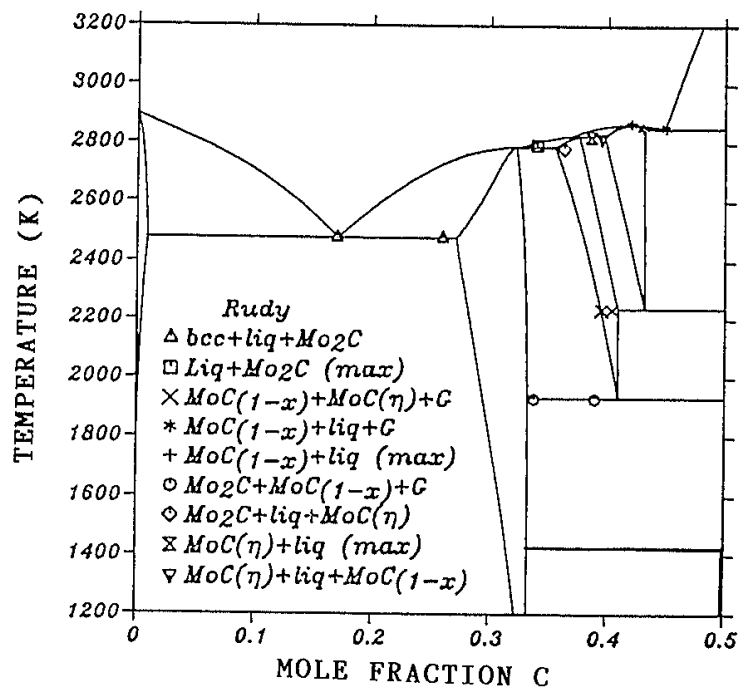

Fig. 3. Computer-calculated Mo-C phase diagram, compared with experimental information.
$\mathrm{Cr}-\mathrm{C}$ system where it is metastable and has never been observed. As another example, $\mathrm{M}_{23} \mathrm{C}_{6}$ may be mentioned for which the quaternary information made

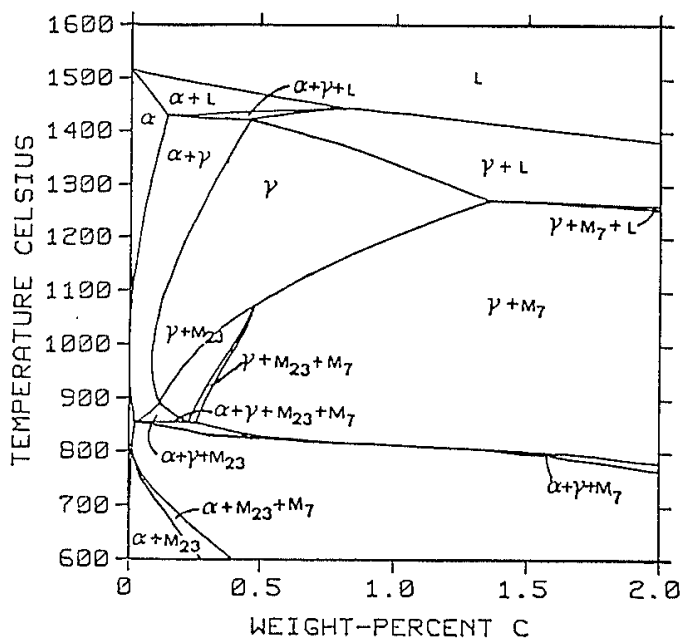

Fig. 4. Computer-calculated vertical section of the FeCr-C system at $13 w t \% \mathrm{Cr}$.

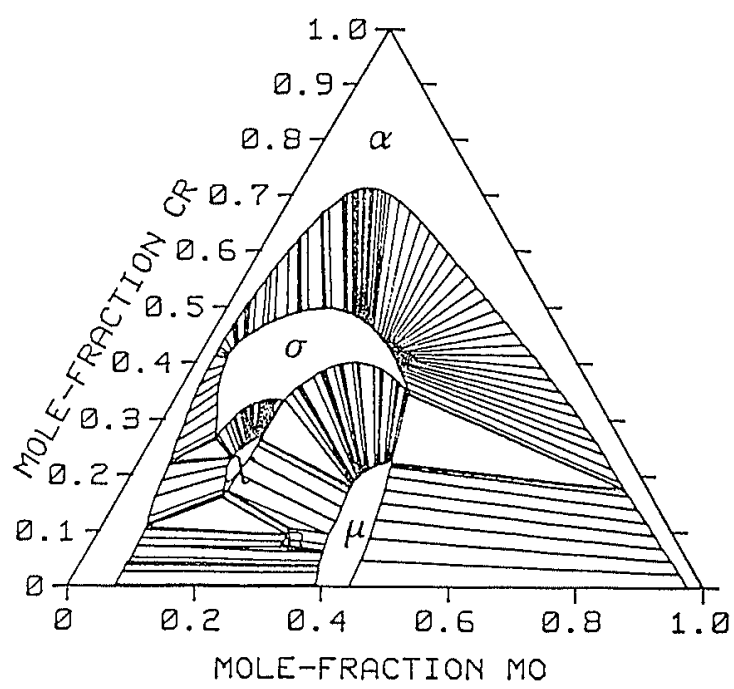

Fig. 5. Computer-calculated isothermal section of $\mathrm{Fe}-\mathrm{Cr}-$ Mo at $1273 \mathrm{~K}$.

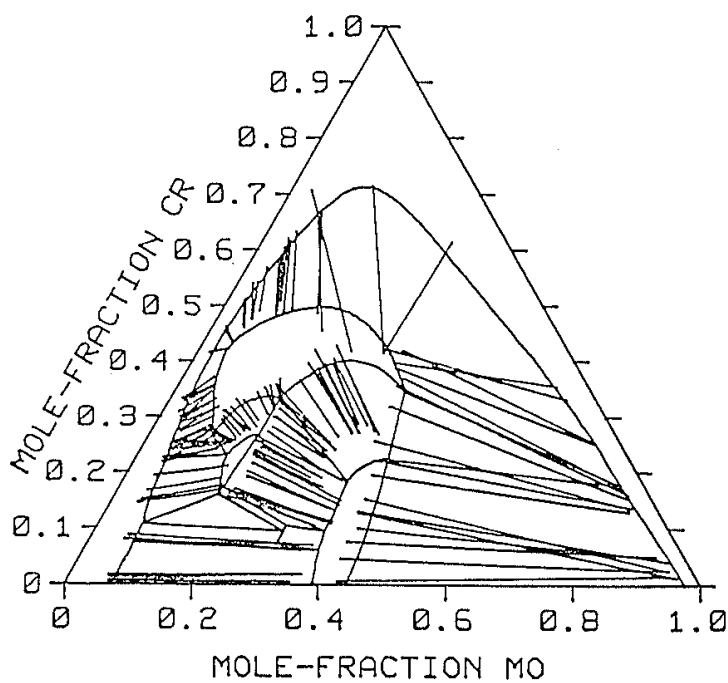

Fig. 6. Computer-calculated isothermal section of $\mathrm{Fe}-\mathrm{Cr}$ Mo at $1273 \mathrm{~K}$, compared with experimental tielines. 


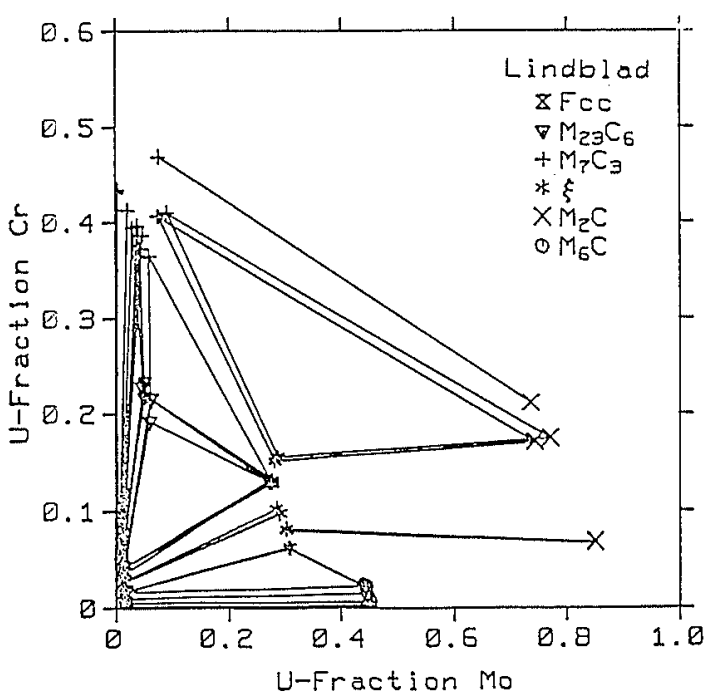

Fig. 7. Experimental tie-lines and tie-triangles in the $\mathrm{Fe}$ $\mathrm{Cr}-\mathrm{Mo}-\mathrm{C}$ system at $1273 \mathrm{~K}$ and $a_{\mathrm{C}}=0.33$.

it necessary to evaluate Gibbs energy for a mixed carbide, $\mathrm{Fe}_{21} \mathrm{Mo}_{2} \mathrm{C}_{6}$, and for the interaction inside the quaternary system. A similar assessment had to be made for the $\mathrm{M}_{6} \mathrm{C}$ carbide.

In the assessment of the $\mathrm{Fe}-\mathrm{Cr}-\mathrm{Mo}-\mathrm{C}$ system it was particularly valuable to have quaternary information on the phase equilibria at constant values of the $\mathrm{C}$ activity. As an example, Fig. 7 shows experimental data at $1273 \mathrm{~K}$ and $a_{\mathrm{C}}=0.33$ and Fig. 8 shows the recalculated diagram. This quaternary diagram looks like an isothermal section of a ternary diagram because it has been sectioned at a constant carbon potential. By the same reason, it is possible to make reaction schemes at constant $T$ where the $\mathrm{C}$ activity varies vertically. See Fig. 9 which resembles a Scheil diagram for a ternary system where $\mathcal{T}$ varies vertically.

\section{2. $\mathrm{Fe}-\mathrm{Cr}-\mathrm{Mo}-\mathrm{W}-\mathrm{C}$}

In a continuation of the work on the $\mathrm{Fe}-\mathrm{Cr}-\mathrm{Mo}-\mathrm{C}$ system, an assessment of the $\mathrm{Fe}-\mathrm{Cr}-\mathrm{W}-\mathrm{C}$ system was made ${ }^{15)}$ and then the quinary system $\mathrm{Fe}-\mathrm{Cr}-\mathrm{Mo}-\mathrm{W}-\mathrm{C}$. was predicted by calculation. ${ }^{16)}$ However, it was then desirable to have assessments of three additional quaternary systems which were not available. An attempt was made to base their descriptions on the ternary systems and estimated values for the new parameters appearing in the quaternary systems.

The result for the quinary system was of particular interest in connection with high-speed steels. The result could thus be checked by comparing with some information obtained with well defined synthetic highspeed steels. ${ }^{17}$ ) That information gave the constitution of several steels at $1473 \mathrm{~K}$ and a constant $\mathrm{C}$ activity. Most of them contained austenite and $\mathrm{M}_{6} \mathrm{C}$. It was possible to obtain reasonably good agreement with this information. It thus seems that a description is now available for predicting the constitution of high-speed steels with some confidence. As an example, Fig. 10 shows a vertical section at $4 \mathrm{wt} \% \mathrm{Gr}$, $6 \mathrm{wt} \% \mathrm{Mo}$ and $6 \mathrm{wt} \% \mathrm{~W}$. The dashed line indicates the composition of a typical high-speed steel. How-

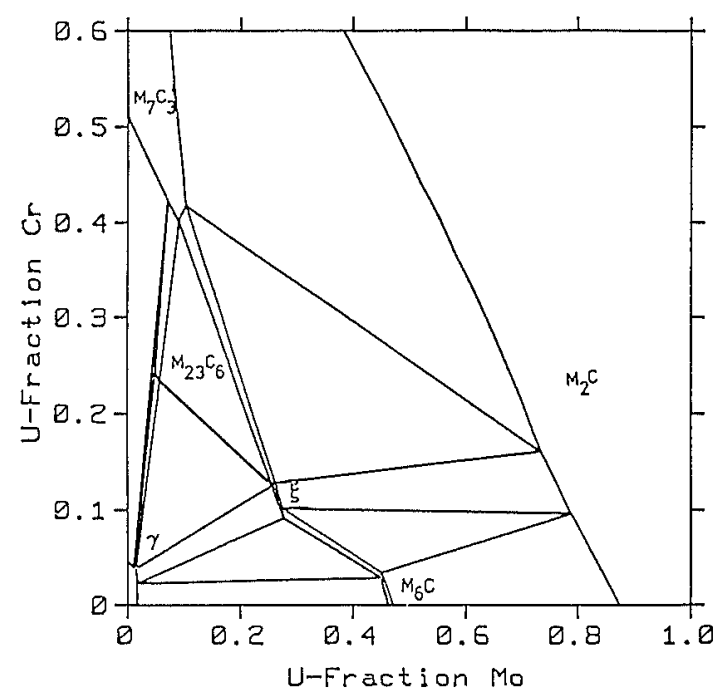

Fig. 8. Computer-calculated isothermal and isoactivity section of the $\mathrm{Fe}-\mathrm{Cr}-\mathrm{Mo}-\mathrm{G}$ system at $1273 \mathrm{~K}$ and $a_{\mathrm{C}}=0.33$.

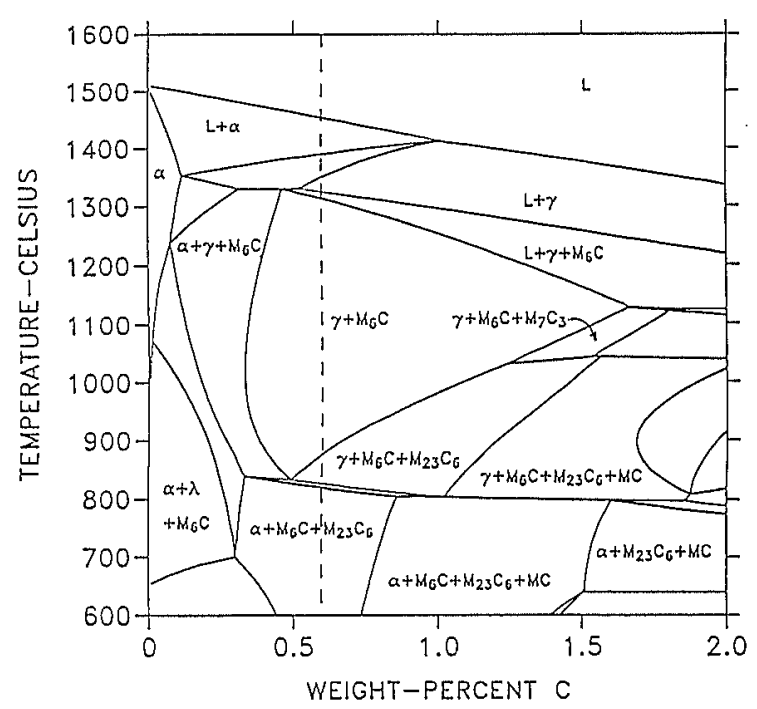

Fig. 10. Computer-calculated vertical section of the $\mathrm{Fe}$ $\mathrm{Cr}-\mathrm{Mo}-\mathrm{W}-\mathrm{C}$ system at $4 \mathrm{wt} \% \mathrm{Cr}, 6 \mathrm{wt} \% \mathrm{Mo}$ and $6 \mathrm{wt} \% \mathrm{~W}$.

ever, it must be emphasized that the important effects of $\mathrm{V}$ and $\mathrm{Co}$ have not yet been included.

\section{3. $\mathrm{Fe}-\mathrm{Ni}-\mathrm{W}-\mathrm{C}$}

The $\mathrm{Fe}-\mathrm{Ni}-\mathrm{W}-\mathrm{C}$ system is particularly interesting as a possible system for making cemented carbides with $\mathrm{Fe}-\mathrm{Ni}$ replacing $\mathrm{Co}$ as the binder phase in WG tools. Due to the similarity between $\mathrm{Fe}$ and $\mathrm{Ni}$, the phase diagram is not very complicated and its main features could be obtained by prediction from the four ternary side-systems. ${ }^{18)}$ However, it was necessary to introduce and assess two quaternary interactions for $\mathrm{M}_{6} \mathrm{C}$ and also a quaternary interaction for the liquid in order to fit some information on the liquidus.

A typical vertical section through the phase diagram is shown in Fig. 11. It is made at $17 \mathrm{wt} \% \mathrm{Fe}$ and $3 \mathrm{wt} \% \mathrm{Ni}$. It is of some practical interest because it shows the conditions for producing a material of $W G+f c c$ and preventing the formation of graphite 


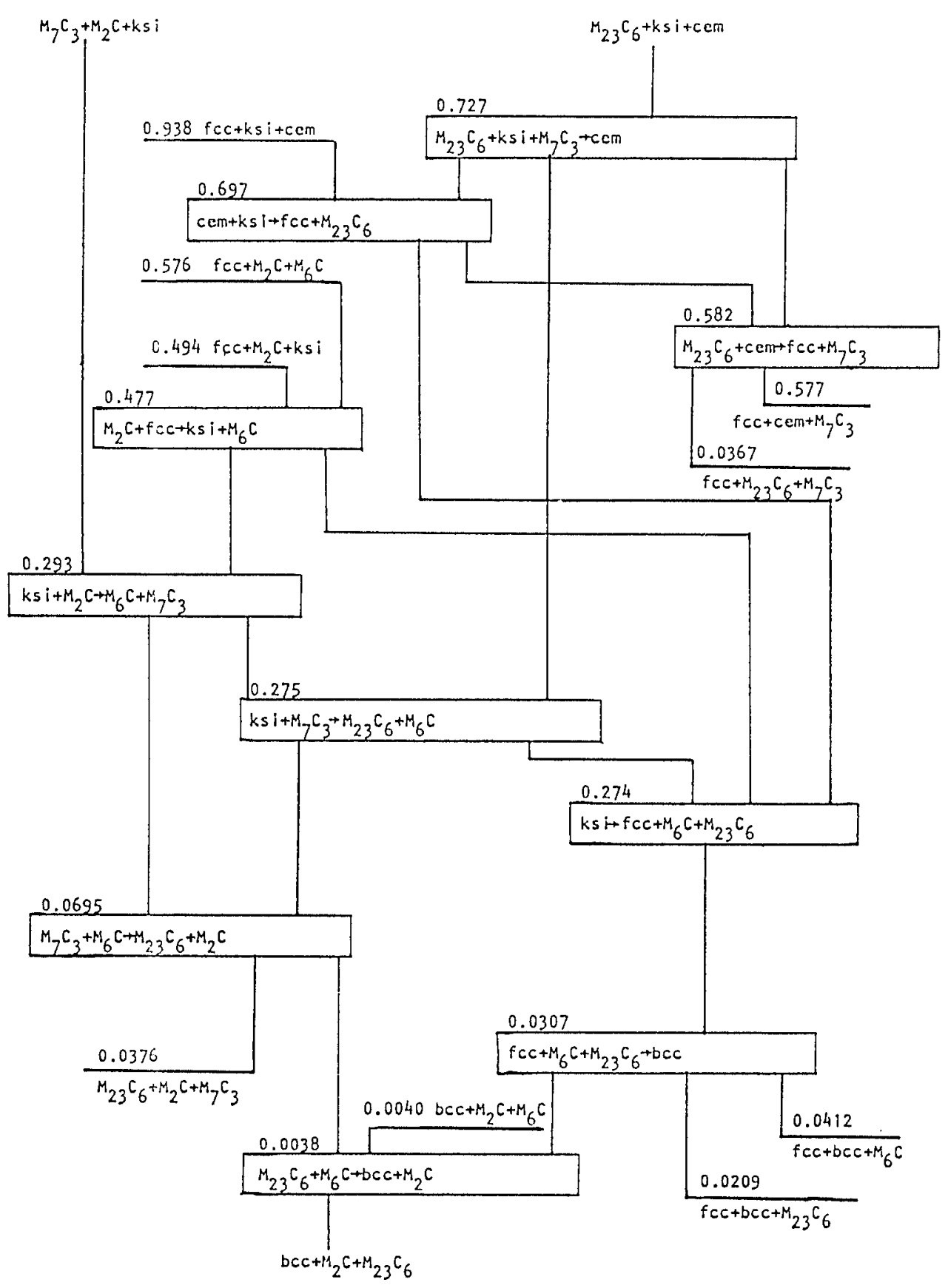

Fig. 9. Reaction scheme of the Fe-Cr-Mo-G system at $1273 \mathrm{~K}$. The numbers give the $\mathrm{C}$ activity values.

if the carbon content is too high and $\mathrm{M}_{6} \mathrm{C}$ if it is too low, both of which are detrimental to the mechanical properties. One may conclude that the $\mathrm{C}$ content should be adjusted between the values 5.03 and 5.16 wt $\%$. Fig. 12 shows how these limits vary with the $\mathrm{Fe}: \mathrm{Ni}$ ratio.

\section{4. $\mathrm{Co}-\mathrm{Fe}-\mathrm{Ni}-\mathrm{W}-\mathrm{C}$}

In a continuation of the work on the $\mathrm{Fe}-\mathrm{Ni}-\mathrm{W}-\mathrm{C}$ system, a calculation was made of the quinary system $\mathrm{Co}-\mathrm{Fe}-\mathrm{Ni}-\mathrm{W}-\mathrm{C}$. ${ }^{19)}$ It was based on assessments of the $\mathrm{Fe}-\mathrm{Ni}-\mathrm{W}-\mathrm{G}, \mathrm{Co}-\mathrm{Fe}-\mathrm{Ni}-\mathrm{C}$ and $\mathrm{Co}-\mathrm{Ni}-\mathrm{W}-\mathrm{C}$ systems. The Co-Fe-Ni-W system was not assessed due to the lack of information but it is probably not too unrealistic to assume that its quaternary interactions are small. Nor was the Co-Fe-W-C system assessed because of lack of information but due to the similarity between $\mathrm{Fe}$ and $\mathrm{Co}$ it was assumed that its quaternary interactions can be neglected. Assessments of all the 10 ternary and 10 binary side-systems were used. With the description of the Co-Fe-Ni-W-C system available, it is now possible to calculate diagrams like Fig. 12 for any Co-Fe-Ni binder phase. As an example, Fig. 13 gives a vertical section at $5 \mathrm{wt} \% \mathrm{Fe}$, $4 \mathrm{wt} \%$ Co and $1 \mathrm{wt} \% \mathrm{Ni}$. The possibility of predicting such phase diagrams can drastically decrease the experimental cost in alloy development. 


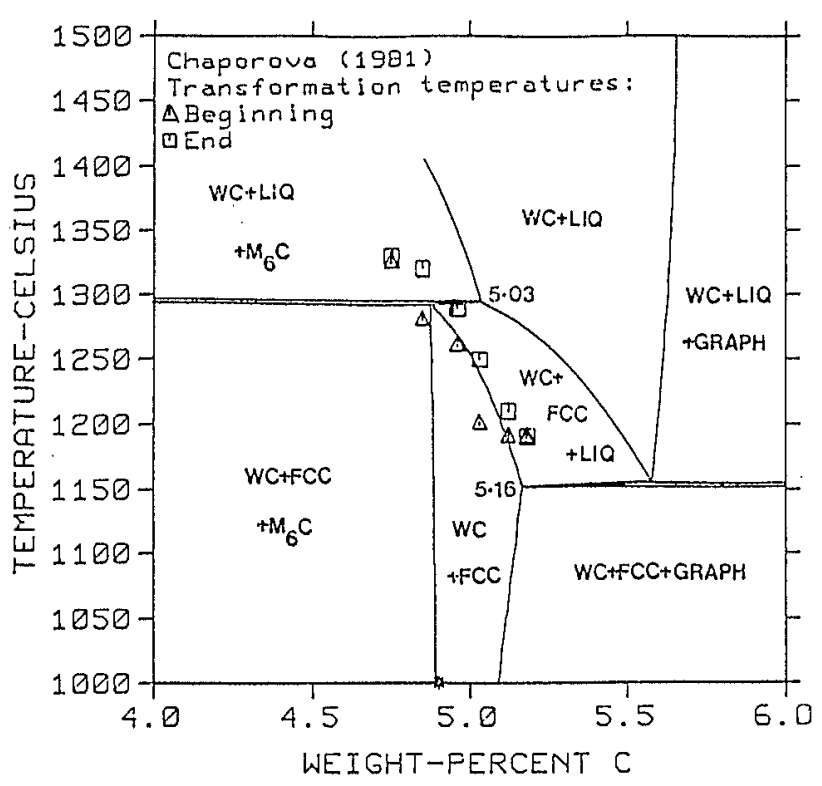

Fig. 11. Computer-calculated vertical section of the Fe$\mathrm{Ni}-\mathrm{W}-\mathrm{G}$ system at $17 \mathrm{wt} \% \mathrm{Fe}$ and $3 \mathrm{wt} \% \mathrm{Ni}$.

\section{A Problem of Consistency}

The $\mathrm{Fe}-\mathrm{Cr}-\mathrm{Ni}-\mathrm{C}$ system is the basis for austenitic stainless steels but also for heat-resistant $\mathrm{Ni}$ base alloys. It is thus important to have a good description across the whole system but when work was to start on this system it was found that there was no ambitious assessment of the $\mathrm{Cr}-\mathrm{Ni}-\mathrm{C}$ system. The work thus started with that ternary side-system but after many attempts it was concluded ${ }^{20)}$ that the solubilities of the $\mathrm{Cr}$ rich carbides in the $\mathrm{Ni}$ rich fcc phase could not be fitted with the present description of the $\mathrm{Cr}-\mathrm{C}$ system. It was thus necessary to go back to that binary. In recent years there has been new information on the properties of the $\mathrm{Cr}$ carbides $^{21}$ and when an assessment was now made, based upon that information, it was also possible to fit the solubility data in the $\mathrm{Cr}-$ $\mathrm{Ni}-\mathrm{C}$ system.

Fig. 14 gives a comparison between different reports on $\mathrm{Cr}_{3} \mathrm{C}_{2}$. The scatter is very large and the previous assessment was based upon the dashed line which may be regarded as a reasonable choice. The new assessment is based upon the solid line. Considering the large scatter of the experimental information one may think that the difference between the two choices is small. This example is an illustration of the fact that information on phase equilibria is sometimes more critical for the determination of thermodynamic properties than direct thermochemical measurements. However, this is not always true. For example, in the present case the $\mathrm{Cr}-\mathrm{C}$ phase diagrams calculated from the two assessments look almost the same. It was thus necessary to go to a higher order system in order to decide on the properties of the $\mathrm{Cr}$ carbides.

The decision to accept a new assessment of the $\mathrm{Cr}-\mathrm{C}$ system was a difficult one because the old assessment had been used as a basis for assessments of a number of ternary systems, $\mathrm{Fe}-\mathrm{Cr}-\mathrm{C}, \mathrm{Mo}-\mathrm{Cr}-\mathrm{C}$,

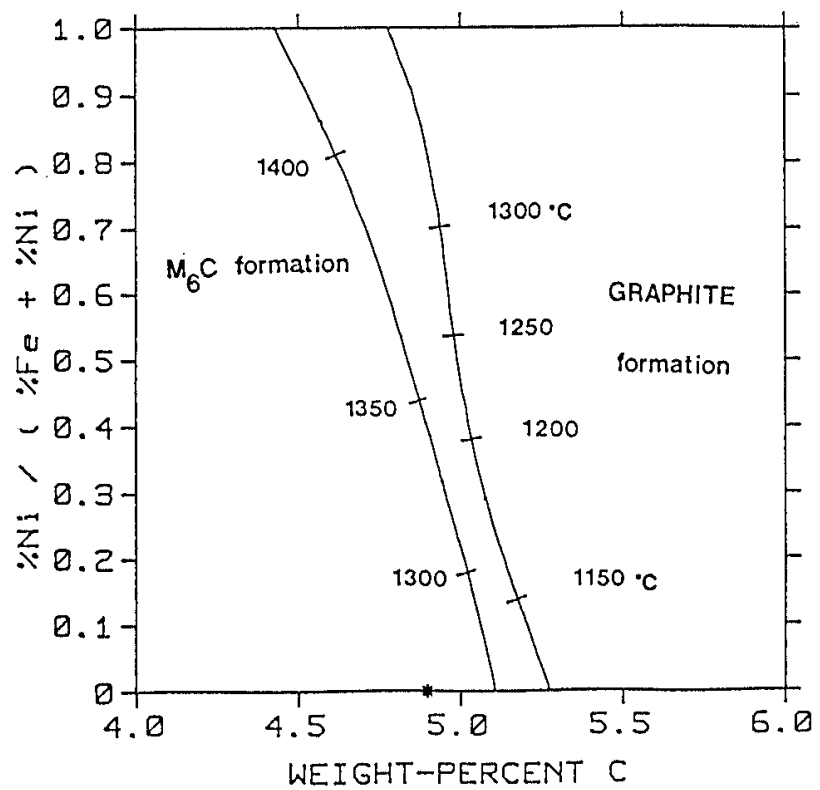

Fig. 12. Temperature projection of a section of the $\mathrm{Fe}-$ $\mathrm{Ni}-\mathrm{W}-\mathrm{C}$ system calculated at $20 \mathrm{wt} \% \mathrm{Fe}+\mathrm{Ni}$.

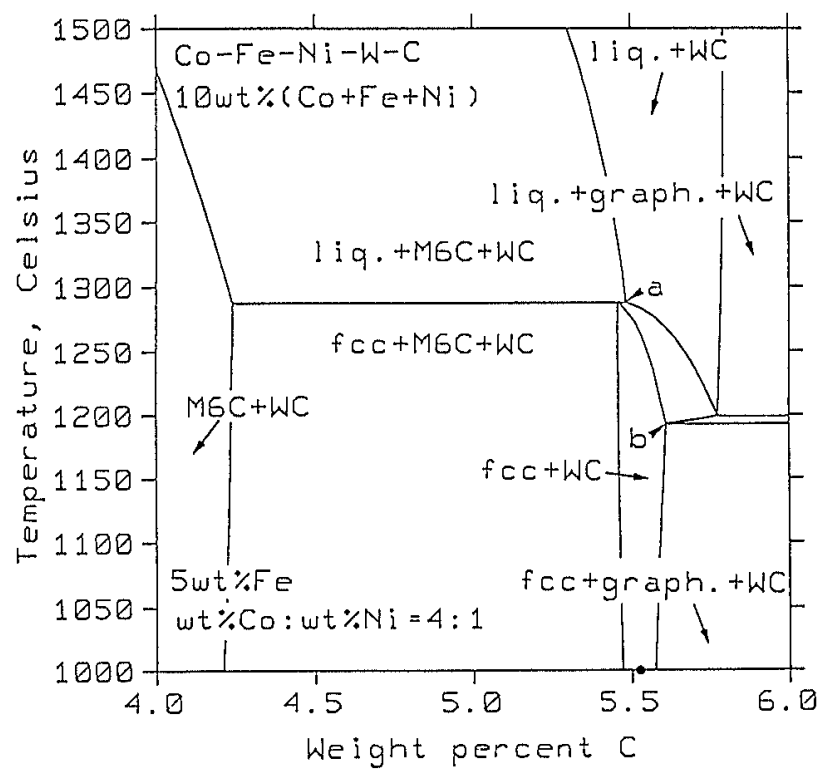

Fig. 13. Computer-calculated vertical section of the Co$\mathrm{Fe}-\mathrm{Ni}-\mathrm{W}-\mathrm{G}$ system at $4 \mathrm{wt} \% \mathrm{Co}, 5 \mathrm{wt} \% \mathrm{Fe}$ and $1 \mathrm{wt} \% \mathrm{Ni}$.

$\mathrm{W}-\mathrm{Cr}-\mathrm{C}$, and several quaternary systems involving them. It will thus be necessary now to reassess most of the systems discussed in the previous sections of this lecture in order to get a consistent database. One may wonder if consistency in the database could be worth such a large effort. The answer is that without consistency the database would be of little use. There is really no alternative. Rather than accept inconsistency, one should accept an inferior fit of some information. As a consequence, in the present situation it will be necessary to have two separate databases, one based on the old $\mathrm{Gr}-\mathrm{G}$ assessment and a separate one based on the new. This second database will primarily be used for stainless steels but may be extended gradually as the other systems are being reassessed. 


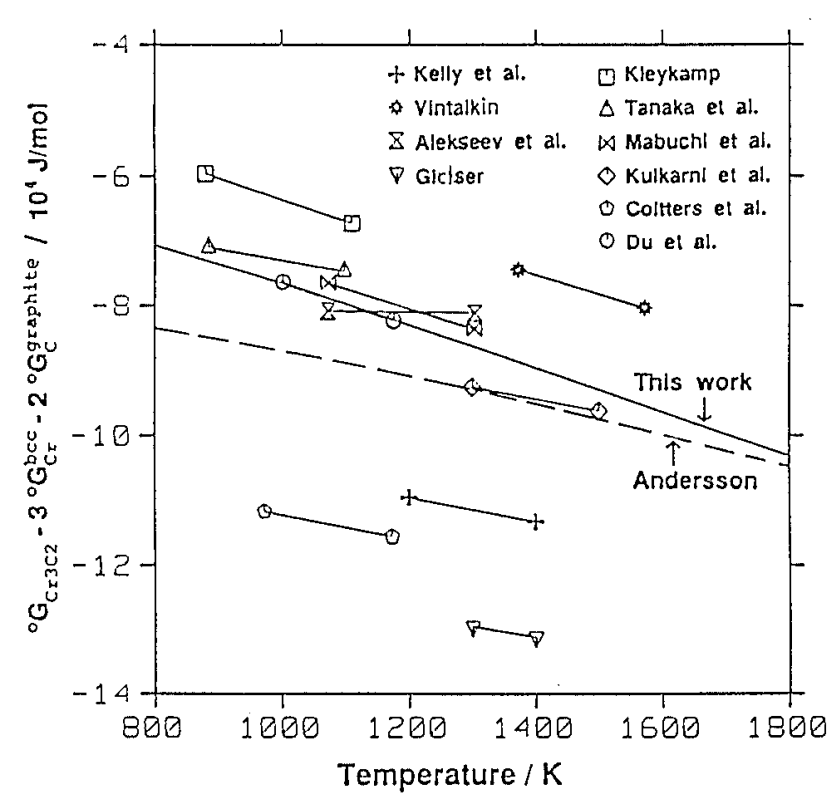

Fig. 14. Gibbs energy of formation of $\mathrm{Cr}_{3} \mathrm{C}_{2}$, according to various authors and two assessments.

It is important to notice that a reassessment is much quicker than the first assessment. Thanks to the computer-operated procedure of the assessment, all the information is already in the computer and the thermodynamic models are already defined. There is still a problem of finding the new optimum when parameter values for a lower order system are changed but the experience gained in the previous assessment is of considerable help. It would be even better if the experience could be stored in the computer and brought to use again in the new assessment. This is something we still have to learn how to do.

\section{1. $\mathrm{Fe}-\mathrm{Cr}-\mathrm{Ni}-\mathrm{C}$}

The assessment of the $\mathrm{Fe}-\mathrm{Cr}-\mathrm{Ni}-\mathrm{C}$ system continued with a reassessment of the $\mathrm{Fe}-\mathrm{Cr}-\mathrm{C}$ system. ${ }^{22}$ ) It was then found that the solubilities of $\mathrm{Cr}$ rich carbides in austenite are not very well established experimentally, especially not at temperatures below 1000 ${ }^{\circ} \mathrm{C}$. On the other hand, these solubilities are very important for the austenitic stainless steels and additional information could thus be obtained from the $\mathrm{Fe}-\mathrm{Cr}-\mathrm{Ni}-\mathrm{C}$ system. As a consequence, the $\mathrm{Fe}-\mathrm{Cr}-$ $\mathrm{C}$ system was assessed together with the $\mathrm{Fe}-\mathrm{Cr}-\mathrm{Ni}-\mathrm{C}$ system.

The assessment of the $\mathrm{Fe}-\mathrm{Cr}-\mathrm{Ni}-\mathrm{C}$ system has now been used for some calculations of the tendency of a steel to be sensitized for intercrystalline corrosion. ${ }^{23)}$ The idea is that, during an unintentional heat treatment, $\mathrm{G}$ may diffuse to the grain boundaries and there cause a precipitation of $\mathrm{Cr}$ rich carbides, thus causing a $\mathrm{Gr}$ depleted zone along the grain boundaries. If the $\mathrm{Cr}$ content falls below a value of about $12 \mathrm{wt} \%$, then the corrosion resistance is low.

Fig. 15 gives a comparison between the solubility of $\mathrm{M}_{23} \mathrm{C}_{6}$ in steels with $8 \mathrm{wt} \% \mathrm{Ni}$ and various $\mathrm{Cr}$ contents and the critical $\mathrm{C}$ content for sensitization. To the left of the first line there will be no precipitation of $\mathrm{M}_{23} \mathrm{C}_{6}$ from the austenitic material. Between the

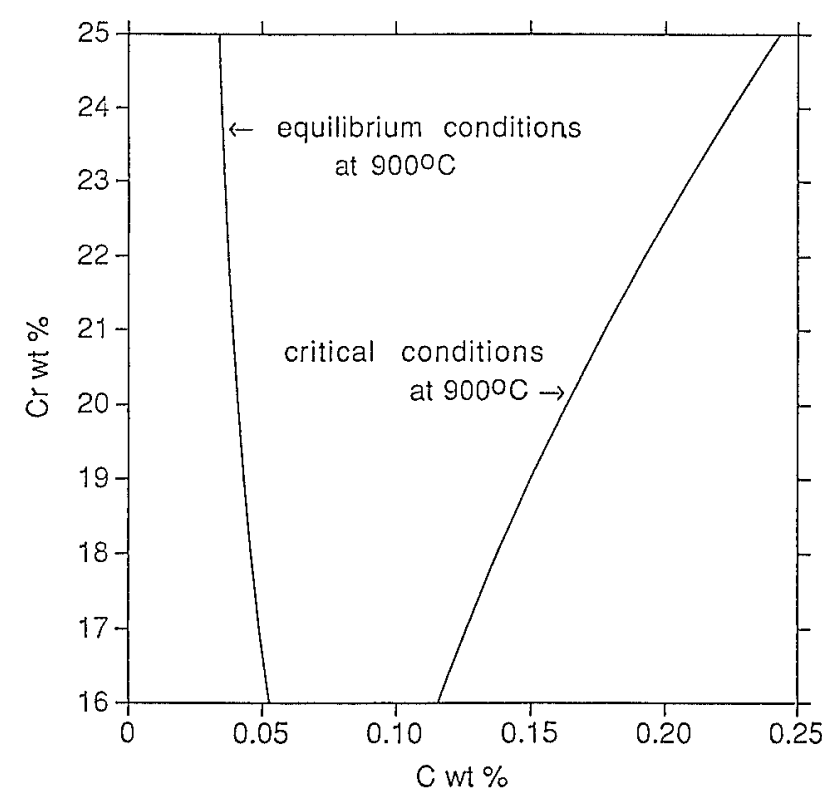

Fig. 15. Computer-calculated precipitation of $\mathrm{M}_{23} \mathrm{C}_{6}$ in austenitic stainless steel with $8 \mathrm{wt} \% \mathrm{Ni}$ and various $\mathrm{Cr}$ contents.

Precipitation can occur to the right of the first curve but makes the steel sensible for corrosion only to the right of the second curve.

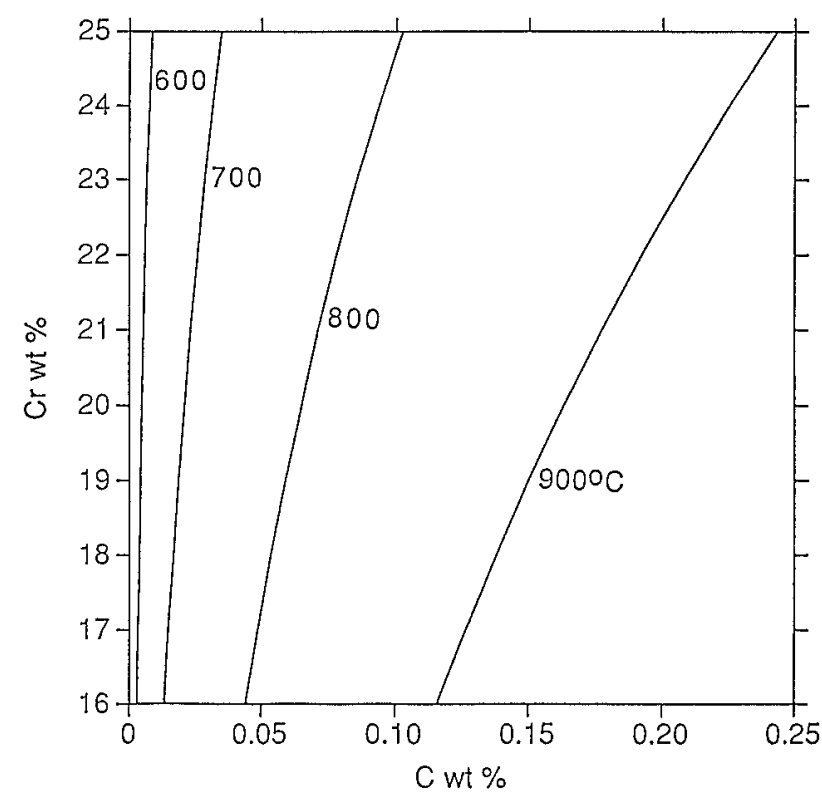

Fig. 16. Computer-calculated curves for the critical conditions for sensitization of austenitic stainless steels of $8 \mathrm{wt} \% \mathrm{Ni}$ and various $\mathrm{Cr}$ contents.

lines there will be precipitation and the zone along the grain boundaries will be more and more depleted of $\mathrm{Cr}$ until it falls below $12 \mathrm{wt} \% \mathrm{Cr}$ to the right of the second line. It is interesting to note that the difference between the two lines increases with the Gr content.

Fig. 16 shows the critical condition for sensitization as function of temperature and it is important to notice that extremely low $\mathrm{G}$ contents are required in order to eliminate the risk of making a steel sensitized by a long enough heat treatment at $600^{\circ} \mathrm{C}$. Before leaving this topic it should be emphasized that the 
phenomenon of sensitization is more complicated than indicated here. It may be stated that the present arguments apply at a very large grain size.

\section{Conclusions}

Even if a database is not perfect and does not give quite accurate predictions, it may be very useful in predicting the effect of a change in composition or temperature. It may thus be used in order to eliminate much experimental work in alloy development. However, it is a requirement that the database is consistent.

Our experience is that the construction of a consistent database requires much more work than separate assessments of the same number of systems. However, the practical use of a consistent database is so much larger that the larger effort is justified.

It is important to continue developing the computer-operated procedures of assessment. At present, many subjective decisions are taken by the assessor during the course of the assessment. That situation may never change and may even be a guarantee of a good result. However, it should be possible to impose such decisions on the computer in a logical language, such that it may be retrieved, considered and applied in a later reassessment.

There will always be a need of reassessments.

\section{Acknowledgement}

The main part of the work described in this lecture has been supported financially by the Swedish National Board for Technical Development.

\section{REFERENCES}

1) L. Kaufman: Phase Stability of Metals and Alloys, ed. by P. S. Rudman, J. S. Stringer and R. I. Jaffee, McGrawHill, New York, (1967), 125.

2) A.T. Dinsdale: SGTE DATA for Pure Elements, NPL Rep. DMA (A) 195, Sept. 1989.

3) B. Sundman: Calculated Binary Phase Diagrams from the SGTE Database on the Thermo-Calc Databank System, Div. Phys. Metall., Royal Inst. Technol., Stockholm,
(1989).

4) M. Hillert, T. Wada and H. Wada: J. Iron Steel Inst., 205 (1967), 539.

5) T. Nishizawa: Scand.J. Metall., 1 (1972), 41.

6) T. Nishizawa: Scand.J. Metall., 6 (1976), 74.

7) B. Jansson: A General Method for Calculating Phase Equilibria under Different Types of Conditions, TRITAMAC 233, Royal Inst. Technol., Stockholm, (1984).

8) B. Jansson: Evaluation of Parameters in Thermochemical Models Using Different Types of Experimental Data Simultaneously, TRITA-MAG 234, Royal Inst. Technol., Stockholm, (1984).

9) B. Sundman, B. Jansson and J.-O. Andersson: CALPHAD, 9 (1985), 153.

10) J.-O. Andersson, A. Fernandez Guillermet and P. Gustafson: CALPHAD, 11 (1987), 361.

11) J.-O. Andersson: CALPHAD, 12 (1988), 1.

12) J.-O. Andersson: Metall. Trans. A, 19A (1988), 627.

13) J.-O. Andersson and N. Lange: Metall. Trans. A, 19A (1988), 1385.

14) J.-O. Andersson: TRITA-MAC 323, Royal Inst. Technol., Stockholm, (1986).

15) P. Gustafson: TRITA-MAG 348, Royal Inst. Technol., Stockholm, (1987).

16) P. Gustafson: TRITA-MAG 354, Royal Inst. Technol., Stockholm, (1987).

17) H. Wisell: An Experimental Study of Carbide/Austenite Equilibria in the High Speed Steel Alloy System, Kloster Speed Steel AB, Söderfors, (1989).

18) A. Fernandez Guillermet: Z. Metallkd., 78 (1987), 165.

19) A. Fernandez Guillermet: TRITA-MAC 374, Royal Inst. Technol., Stockholm, (1988).

20) M. Kajihara and M. Hillert: Metall. Trans. A, 21A (1990), (in print).

21) S. Du, S. Seetharaman and L.-I. Staffansson, Royal Inst. Technol., Stockholm, Unpublished work.

22) M. Hillert and Caian Qiu: TRITA-MAG 420, Royal Inst. Technol., Stockholm, (1990).

23) M. Hillert and Caian Qiu: Prediction of Loss of Corrosion Resistance in Austenitic Stainless Steels, Div. Phys. Metall., Royal Inst. Technol., Stockholm, (1990).

(Based on the Yukawa Memorial Lecture delivered by Professor Hillert at the 119th ISIJ Meeting, April 3, 1990, at Tokyo Institute of Technology in Tokyo) 